\title{
Effect of laser power and deposition environment on the microstructure and properties of direct laser metal-deposited $12 \mathrm{CrNi2}$ steel
}

\author{
Mohamad Ebrahimnia ${ }^{1} \cdot$ Yujiang Xie $^{1} \cdot{\text { Changtai } \mathrm{Chi}^{2}}^{2}$
}

Received: 24 May 2019 / Revised: 25 July 2019 / Published online: 2 December 2019

(c) The Chinese Society for Metals (CSM) and Springer-Verlag GmbH Germany, part of Springer Nature 2019

\begin{abstract}
Direct laser metal deposition was used for preparing blocks of steel $12 \mathrm{CrNi} 2$ using four different laser powers under two different deposition environments including atmospheric environment and Ar-protected chamber. The results showed that microstructures and mechanical properties were significantly affected by different laser powers. Increasing laser power and deposition in Ar chamber will lead to a decrease in the quantity and size of the voids, which brings more elongation to the samples. Bainitic microstructure was replaced by Widmanstatten ferrite and pearlite, and the amount of proeutectoid ferrite increased with increasing laser power. Moreover, microstructures of previous layers were completely altered in high laser power. Excessive heat accumulation by using high heat input can produce equiaxed ferritic grains with the pearlites in previously deposited layers. Hardness of deposited samples increased from the bottom layer toward the top layer. By using a diode laser with a spot diameter size of $2 \mathrm{~mm}$, the $900-\mathrm{W}$ laser power is suitable for producing crack- and void-free samples. However, post-deposition heat treatment is necessary for obtaining homogeneous desired microstructure and grain size in the manufactured samples.
\end{abstract}

Keywords Direct laser metal deposition $\cdot$ Bainite $\cdot$ Equiaxed ferrite $\cdot$ Void $\cdot$ Steel $\cdot$ Microstructure $\cdot$ Mechanical properties Rapid solidification

\section{Introduction}

Direct laser metal deposition (DLMD) is a main additive manufacturing method which not only can produce a variety of components but also is a promising method for remanufacturing and rebuilding worn components [1-3]. $12 \mathrm{CrNi} 2$ is a common steel which is used in many applications including shafts and structural components. There are some investigations about this steel for manufacturing high-duty components. Dong et al. [4] investigated the effect of oxygen content on microstructures and mechanical properties of this steel using direct laser metal deposition. Their results showed that a little

Available online at http://link.springer.com/journal/40195.

Yujiang Xie

Yjxie@imr.ac.cn

1 Zhejiang Handsome Intelligent Remanufacturing Technology Co. Ltd, Jiaxing 314000, China

2 Institute of Metal Research, Chinese Academy of Sciences, Shenyang 110016, China amount of oxygen in the powder can adversely affect the mechanical properties of DLMD part and components. Chen et al. [5] investigated the effect of scanning speed on the microstructure of $12 \mathrm{CrNi} 2 \mathrm{Re}$ steel using laser additive manufacturing. They found that the microstructure of steel changes due to the different heat inputs, confirming an optimal scanning speed of $5 \mathrm{~mm} / \mathrm{s}$ owing to the decrease in granular bainite size. Some researches revealed that additions of different elements like $\mathrm{Ce}$ into deposited alloy in laser remanufacturing of $12 \mathrm{CrNi} 2$ steel may improve mechanical properties [6]. Recently, Zhou et al. [7] have investigated the effect of laser power on bainite evolution and mechanical properties of $12 \mathrm{CrNi} 2$ alloy. They found that the bainite morphologies depend on the laser power and the sample fabricated at $2000 \mathrm{~W}$ had the highest mean microhardness and the best combination of ultimate tensile strength and elongation. Wang et al. [8] studied the effect of fabrication atmosphere condition on microstructure and mechanical properties of DLMD-manufactured stainless steel 17-4 PH, and they found that the samples produced in air possessed higher tensile strength and hardness than that in Ar chamber condition. The observed effect can be attributed to the amorphous 
oxide dispersed particles in the samples which were deposited in air. The samples, which were deposited in Ar chamber, had lower porosity because of the heat accumulation in the sample.

There are different process parameters to affect the microstructure and properties of DLMD-manufactured components. Heat input is the main parameter which can be controlled by laser power or scanning speed. Another parameter is the deposition environment. As DLMD method can be used in remanufacturing and rebuilding worn components, it is of a great importance to address main differences between deposition in unprotected and protected environments. Since DLMD has multilayer nature and different microstructures of parts will give different responses to the post-deposition heat treatment, it is important to investigate the microstructure of different heights of deposited sample. In this research, four different laser powers were used to evaluate microstructural characteristics of different heights of DLMD samples in two different deposition environments.

\section{Experimental}

Chemical composition of $12 \mathrm{CrNi} 2$ alloy powder, which was used for laser deposition, is listed in Table 1. Figure 1 shows the particle size distribution of $12 \mathrm{CrNi} 2$ powder which was measured by dry laser particle size analyzer (model HELOS I RODOS). The results show that mean particle size (D50) was about $110 \mu \mathrm{m}$. DLMD part was printed using a Laserline LDF 3000-60 semiconductor laser equipment with a spot diameter size of $2 \mathrm{~mm}$ on the 304 stainless steel substrate. The powder was fed to the substrate using a coaxial feeding system installed on the laser beam nozzle. Samples were deposited using four different laser powers under two different environments. First set of samples was printed in the atmospheric environment with argon flow rate of $3.7 \mathrm{Lit} / \mathrm{min}$ for protection of molten pool. The second set of samples was laser-printed in the fully Ar-protected chamber. For properly addressing samples in the present manuscript, the samples are named according to laser power and environment. Samples L500, L700, L900, and L1 100 were printed in the atmospheric environment using laser power of 500,700, 900, and $1100 \mathrm{~W}$, respectively. Samples AR500, AR700, AR900, and AR1100 were printed in argon-protected chamber using laser power of $500,700,900$, and $1100 \mathrm{~W}$, respectively. For all the samples, the scanning speed and powder feed rate are constant with values of $10 \mathrm{~mm} / \mathrm{s}$ and $6.76 \mathrm{~g} / \mathrm{min}$, respectively. Overlap ratio was $50 \%$ between deposited tracks. The thickness of each layer was about $0.45 \mathrm{~mm}$, and each sample mainly consists of almost

Table 1 Chemical composition of $12 \mathrm{CrNi} 2$ steel powder (wt \%)

\begin{tabular}{llllll}
\hline $\mathrm{C}$ & $\mathrm{Ni}$ & $\mathrm{Cr}$ & $\mathrm{Mn}$ & $\mathrm{Si}$ & $\mathrm{Fe}$ \\
\hline 0.12 & 1.83 & 0.85 & 0.46 & 0.24 & Bal. \\
\hline
\end{tabular}

23 layers. Schematic of the printed sample and laser scanning pattern are shown in Fig. 2. Each layer was deposited from the start point of the previous layer. The process parameters are listed in Table 2. Each sample was printed in the shape of a cuboid with a rectangular base of length $70 \mathrm{~mm}$ and width $20 \mathrm{~mm}$ with a height of $10 \mathrm{~mm}$.

For studying the microstructure of samples, different samples were cut from the top layer, middle area, and bottom area of each printed cuboid sample (Fig. 2). These samples were prepared according to the standard metallographic methods including rough abrasive grinding using $\mathrm{SiC}$ waterproof papers with grid number of 160, 240, 400, 600, 800, 1200 , and 2000 and then polished with diamond paste of 2.5 , 1 , and $0.5 \mu \mathrm{m}$ size. Prepared samples were etched using Nital (4\% nitric acid in ethanol) for $5 \mathrm{~s}$ and then were rinsed with

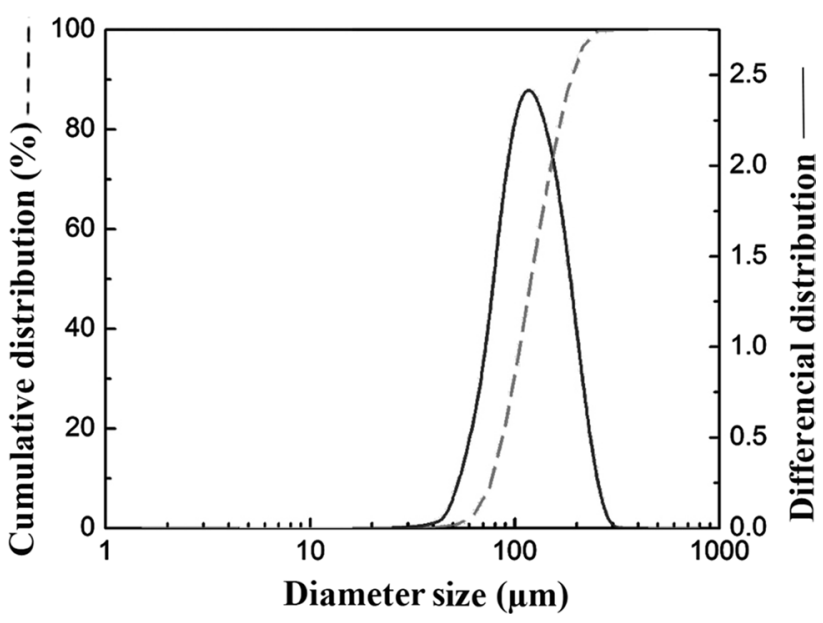

Fig. 1 Particle size distribution of $12 \mathrm{CrNi} 2$ steel powder

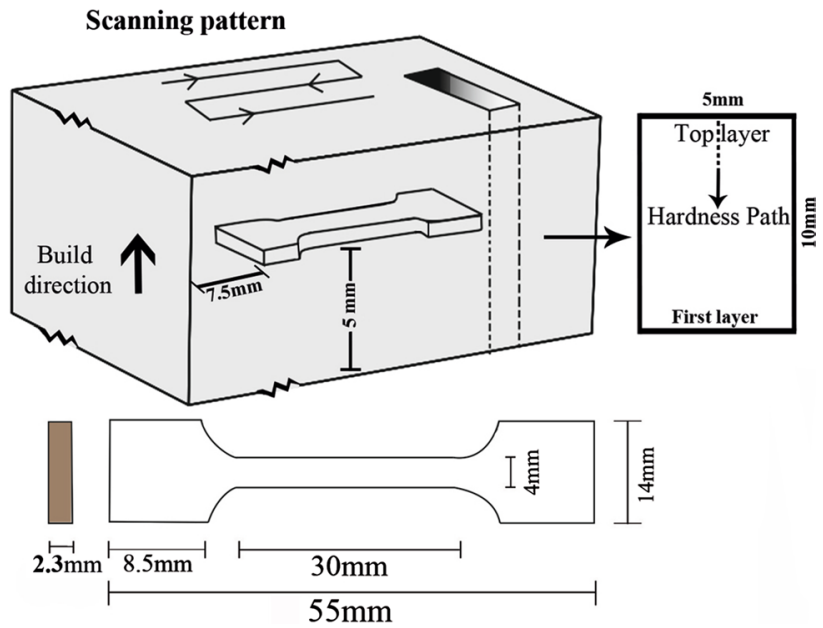

Fig. 2 Schematic illustration of the deposited sample, scanning pattern, position of the extracted tensile sample and metallographic sample 
Table 2 Process parameters of DLMD samples

\begin{tabular}{llrlll}
\hline Sample & Deposition environment & $P(\mathrm{~W})$ & $V(\mathrm{~mm} / \mathrm{s})$ & $\begin{array}{l}\text { Powder feed rate } \\
(\mathrm{g} / \mathrm{min})\end{array}$ & $\begin{array}{l}\text { Heat input } \\
\left(\mathrm{W} / \mathrm{mm}^{2} .\right. \\
\left.\mathrm{s}^{-1}\right)\end{array}$ \\
\hline L500 & Air & 500 & 10 & 6.76 & 25 \\
L700 & Air & 700 & 10 & 6.76 & 35 \\
L900 & Air & 900 & 10 & 6.76 & 45 \\
L1100 & Air & 1100 & 10 & 6.76 & 55 \\
AR500 & Ar chamber & 500 & 10 & 6.76 & 25 \\
AR700 & Ar chamber & 700 & 10 & 6.76 & 35 \\
AR900 & Ar chamber & 900 & 10 & 6.76 & 45 \\
AR1100 & Ar chamber & 1100 & 10 & 6.76 & 55 \\
\hline
\end{tabular}

alcohol and dried under heat blower. The microstructural characteristics were studied by using NanoNova FESEM equipped with energy-dispersive X-ray (EDX) analysis system. Two tensile test samples were cut and machined from each specimen and were tested using INSTRON 5582 electronic universal testing machine at a strain rate of $2.7 \times 10^{-4}$ $\mathrm{s}^{-1}$. Hardness test was carried out by using digital display auto turret microhardness tester TMVP-1 with a load of 100 gr and $15 \mathrm{~S}$ dwell time. Material phase evolution during cooling from melting temperature was calculated using dynamic simulation software JMatPro.

\section{Results and discussion}

\subsection{Microstructural analyses}

Microstructures of the top layers of samples L500-L1100 are shown in Fig. 3. Since the cooling rate in laser deposition is very high, the microstructure is non-equilibrium. Bainitic microstructure can be observed in the top layers of different samples. Proeutectoid ferrite $(\mathrm{PF})$, granular bainite (GB), and some coalesced bainite (CB) can be seen in samples L500 and L700 (Fig. 3a and 3b). Figure 3c and $\mathrm{d}$ shows overall microstructures of the top layers of samples L900 and L1100, respectively. In these samples, bainite size is larger than samples L500 and L700. Moreover, more proeutectoid ferrite and Widmanstatten ferrite (WF) can be seen in these samples. These ferrite morphologies appear because of higher heat input involved in deposition of these samples, which leads to the lower cooling rate when other parameters are constant. It is worth noting that, due to a very low amount of carbon and other alloying elements in steel $12 \mathrm{CrNi} 2$, only a small amount of martensite can be formed in this alloy.

Figure 4 shows microstructures of the middle area of DLMD samples L500 to L1100. The microstructures of middle areas of samples L500 and L700 are nearly same as top areas comprising very fine non-equilibrium bainite and some proeutectoid ferrites (Fig. 4a, b). In contrast, the middle areas of samples L900 and L1100 comprise more equilibrium phases including small pearlite regions distributed between equiaxed ferritic grains (Fig. 4c, d).

Figure 5a, b shows the microstructures of the top layer of samples AR500 and AR700 which consist of very fine bainitic microstructure, similar to laser-deposited samples in air, except there are more proeutectoid ferrite and lath bainites (LB) in these samples. Figure 5c, d shows the microstructures of the top layer of sample AR900 and AR1100 which comprise larger proeutectoid ferrite accompanied with some Widmanstatten ferrites and granular bainite inside prior austenite grains. Proeutectoid ferrite nucleates at the prior austenite grain boundaries, and the size of proeutectoid ferrite increases with increasing laser power. One can see the larger plates of proeutectoid ferrite and bainite sheaves and also some dark pearlite bundles in sample AR1100.

Microstructures of middle part of samples AR500 to AR1100 can be seen in Fig. 6. The middle layer of sample AR500 consists of very fine granular bainite which shows that the microstructure of DLMD sample with laser power of $500 \mathrm{~W}$ was not altered significantly in different layers. However, the middle layers of sample AR700 consist of more granular bainite and some newly formed ferritic grains (F). Deposited microstructure altered completely in sample AR900 and AR1100 in middle layers (Fig. 6c, d). Therefore, larger ferrite blocks with some small ferritic grains and some pearlitic regions can be seen in sample AR900. Sample AR1100 also has large ferritic grains which grow at the expense of small ferritic grains. In this sample, as-deposited microstructure changed to semi-equiaxed ferrite-pearlite microstructure.

Figure 7 shows micrographs of different layers of sample AR1100 in different heights. Moving from top layer toward bottom layer, the pearlite amount and ferritic grain size increased. At the middle area of sample, newly formed ferritic grains appear because of recrystallization. At the lower 


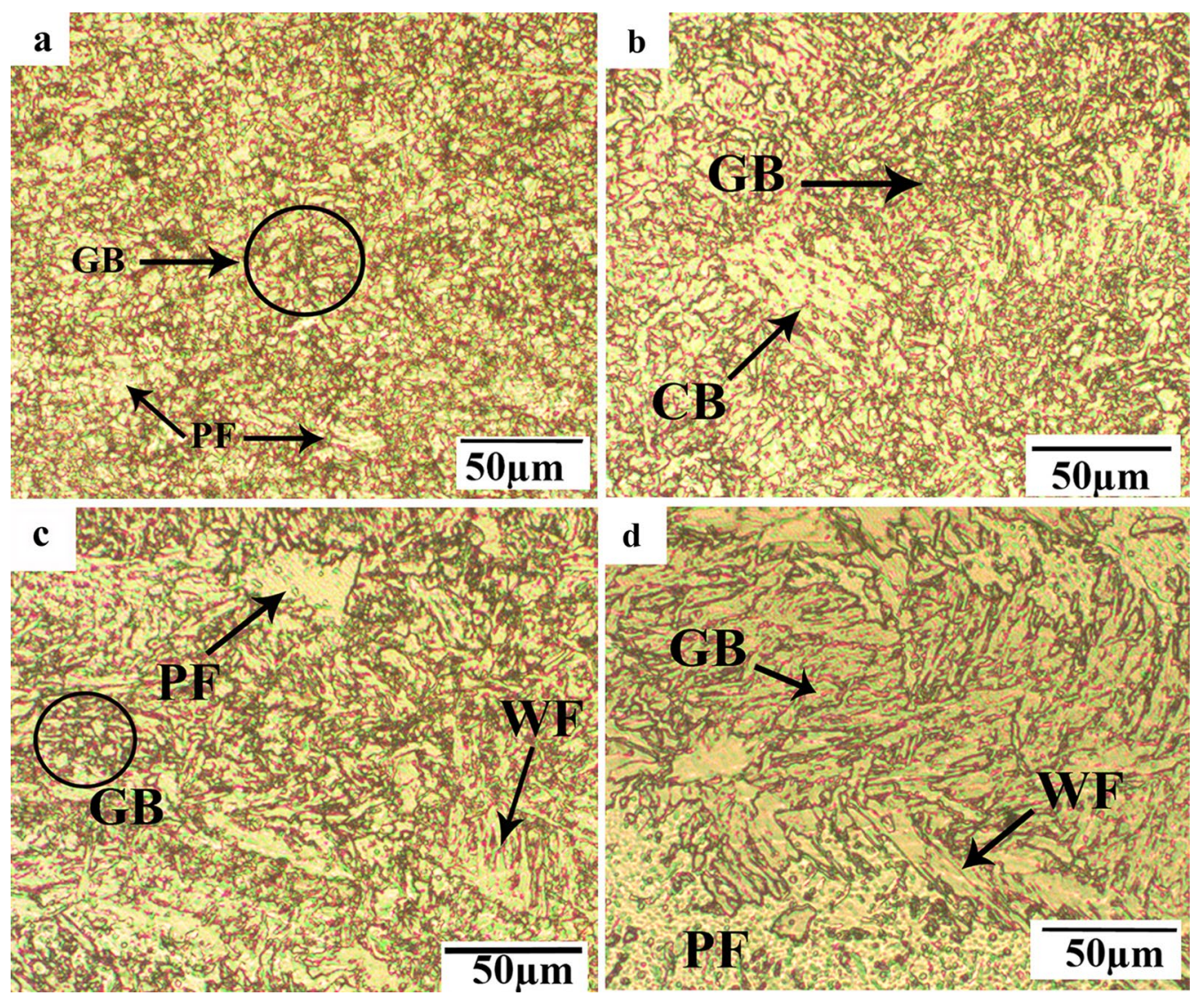

Fig. 3 Micrographs of the top layers of DLMD samples: a L500, b L700, c L900, d L1100. Granular bainite (GB), coalesced bainite (CB), Widmanstatten ferrite $(\mathrm{WF})$, proeutectoid ferrite $(\mathrm{F})$

part of the sample, grain growth and microstructural alteration can be clearly observed.

For better understanding the phase evolution of DLMD samples, one can observe the phase evolution of steel $12 \mathrm{CrNi} 2$ with different cooling rates at high temperature in Fig. 8. High cooling rate as $100^{\circ} \mathrm{C} / \mathrm{s}$ can produce microstructures consisting of mostly bainite alongside some proeutectoid ferrite and martensite in the room temperature. When the samples are laser-deposited using low laser power, the same situation can happen due to the lower heat accumulation and higher cooling rate for these samples. Fine microstructure shows that grain refinement and grain growth cannot occur in samples L500 and L700 (Figs. 4a, b, Fig. 6a). When other parameters including sample size, scanning speed, environment, etc., are constant, higher heat input can lead to the lower cooling rate. In Fig. 8b, when cooling rate decreased to $50{ }^{\circ} \mathrm{C} / \mathrm{s}$, no martensite forms and the microstructures consist of bainite and ferrite. During DLMD process, heat accumulation can lower the cooling rate, especially when the temperature drops below austenitic temperature. Some researchers measured the heat distribution in multi-track cladding, showing the temperature at the clad track can be easily increased to $450-600{ }^{\circ} \mathrm{C}$ in the vicinity and at the previous deposited clad tracks [9-11]. When looking at Fig. 8a, at a temperature of $400{ }^{\circ} \mathrm{C}$, the phases can be proeutectoid ferrite, bainite, and austenite. Assuming that the sample has been preheated to $300-400{ }^{\circ} \mathrm{C}$ and then cooling rate decreases dramatically at this temperature, a large amount of austenite can be found in intergranular areas which can transform to pearlite in further slow cooling to the room temperature. When laser power increases, the pearlitic structure increases in the top and middle areas of the sample. Furthermore, when heat input increases from $25 \mathrm{~W} / \mathrm{mm}^{2} \cdot \mathrm{s}^{-1}$ for laser power of $500 \mathrm{~W}$ to $55 \mathrm{~W} / \mathrm{mm}^{2} . \mathrm{s}^{-1}$ for laser power of $1100 \mathrm{~W}$, the excessive heat accumulation can cause annealing in previously deposited layers, and as it was shown before, equiaxed annealing ferrite can be seen in the middle and lower parts of samples L900, L1100, AR900, and AR1100.

SEM images of the top area of sample AR500 in Fig. 9a reveal different bainite types, proeutectoid ferrite, and martensite-austenite (M-A) constitutes. Higher magnification of the top layers of sample AR700 can be seen in Fig. 9b. In this sample, the microstructure consists of grain boundary Widmanstatten ferrite, granular bainite, and a small amount of lath bainite. In comparison with AR500, the amount of 

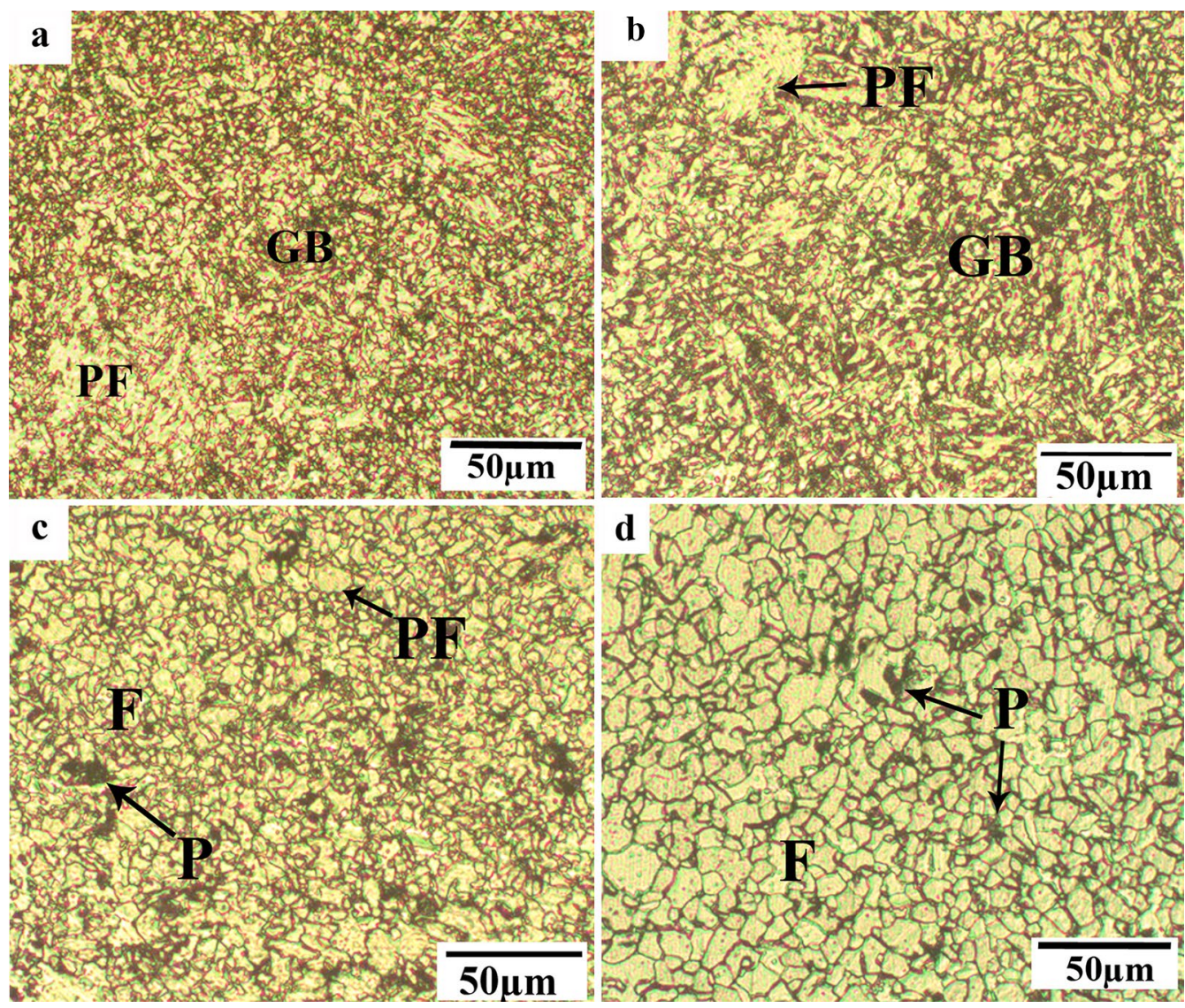

Fig. 4 Micrographs of the middle layers of DLMD samples: a L500, b L700, c L900, d L1100. Granular bainite (GB), proeutectoid ferrite (PF), equiaxed ferrite $(\mathrm{F})$, pearlite $(\mathrm{P})$

M-A constitutes decreased. Figure $9 \mathrm{c}$ shows the middle part of the sample AR700 which consists of newly nucleated ferrite blocks along with some fingerprint-like areas which are pearlites. These pearlites were mentioned as degenerate pearlites by some researchers $[12,13]$. The bainitic microstructure was completely replaced by equiaxed ferrite along grain boundary degenerate pearlite which shows the middle area of the sample experienced very high temperature when depositing top layers.

According to the research by Jung et al. [14], when austenite transformation occurs at high temperature for a longer time associated with lower cooling rates, Widmanstatten ferrite can occur along proeutectoid ferrites at the austenite grain boundaries. Microstructures of top layers of samples, which were deposited by laser power of 900 and $1100 \mathrm{~W}$, also show these phases in Fig. 3c and Fig. 5c. Moreover, middle and lower parts of DLMD samples can be preheated, especially in high laser power. Therefore, any retained austenite may decompose during preheating. According to Bhadeshia [15], at early stages of preheating, decomposition of carbon-rich austenite to ferrite and cementite occurs. Continued tempering can lead to the recrystallization of the ferrite plates into equiaxed grains. Although, in Fig. 8b, no pearlite is predicted in microstructure, different samples in this experiment show the presence of pearlite. According to the literature $[15,16]$, pearlite formation can occur in lowcarbon steels from carbon-rich austenite at high temperatures due to the incomplete bainite transformation. According to the Klier and Lyman, bainitic transformation from carbon-depleted austenite often stopped before completion, while transformation of austenite to ferrite and cementite can start before bainite formation initial time [10, 17]. Therefore, in a low alloy steel which has high tempering temperature, the transformation of austenite to ferrite and cementite can occur during cooling to room temperature at low and moderate cooling rates.

\subsection{Mechanical properties}

Tensile test results of different samples are shown in Fig. 10a, b. Average values of yield strength, ultimate strength, and elongation can be observed in Table 3. In atmospheric and Ar-protected deposited samples, the ultimate strength and yield strength decrease with increasing 


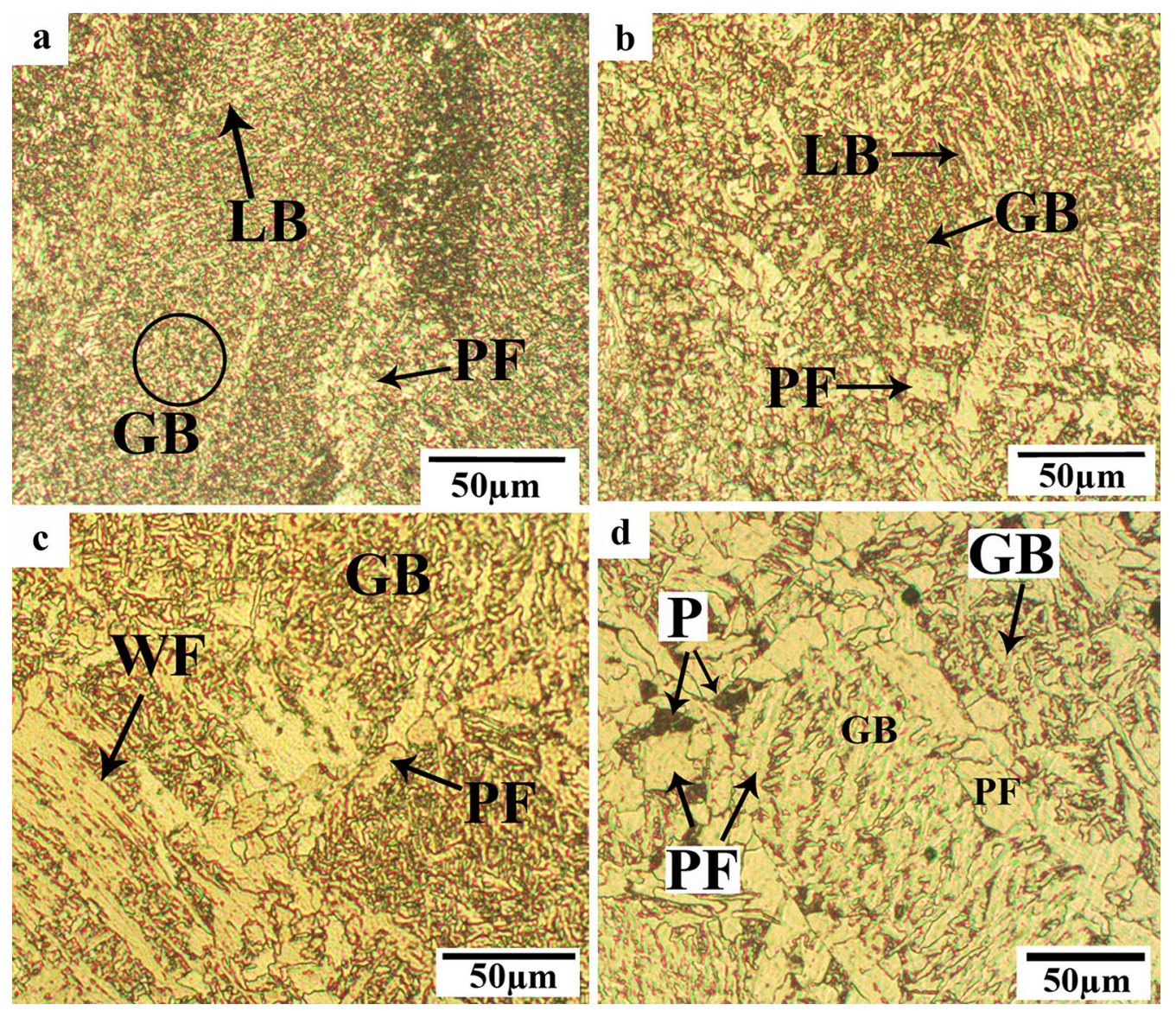

Fig. 5 Micrographs of the top layers of DLMD samples: a AR500, b AR700, c AR900, d AR1100. Granular bainite (GB), proeutectoid ferrite $(\mathrm{PF})$, Widmanstatten ferrite (WF), pearlite (P), lath bainite (LB)

laser power. However, elongation increases with increasing laser power in these samples. The strength and elongation of as-deposited samples L500 and AR500 are comparable with the result of the samples prepared by Zhou et al. [5]. However, the strength of samples dramatically decreased in samples L900 and AR900. All samples show extensive necking before fracture, except samples L500 and L700 which show a negligible amount of necking. This can be observed in Fig. 10a and b. Measuring total area below stress-strain curve can be considered as static toughness of the sample. This value first decreases with increasing power from 500 to $700 \mathrm{~W}$ and then increases with increasing laser power in other deposited samples.

Vickers hardness numbers (HVN) of different samples can be observed in Fig. 11. As it is expected from tensile test results, overall hardness of samples decreases with increasing laser power. Samples L500 and AR500 have the highest hardness values, and samples L1100 and AR1100 have the lowest values. Furthermore, there is an overall increasing trend in hardness from bottom layer toward top layer in most of the samples. In other words, hardness value increases along build direction. Wang et al. also observed that the hardness increased from substrate toward top surface of functionally graded stainless steel which was fabricated by direct laser metal deposition [18]. They associated hardness changes with the microstructural evolution and different grain sizes along build direction. Different mechanical properties of different samples can be associated with microstructure and internal defects. Higher hardness of the samples L500 and AR500 can be associated with a very fine grain structure and the presence of bainite and M-A islands in the microstructure. With decreasing bainite and increasing equiaxed ferrite in the samples, hardness decreased. Major changes in strength and hardness occurred because the microstructure coarsened with increasing laser power in DLMD samples or with the onset of recrystallization, where the bainite plates were replaced by equiaxed ferritic grains [10].

In addition to the microstructure, grain size also has a significant effect on the material strength. When grain size of sample increases, the tensile strength decreases. This phenomenon is well developed by Hall-Petch equation [19]. Grain size of the middle areas of different samples can be seen in Fig. 12. By using intercept method, some horizontal 


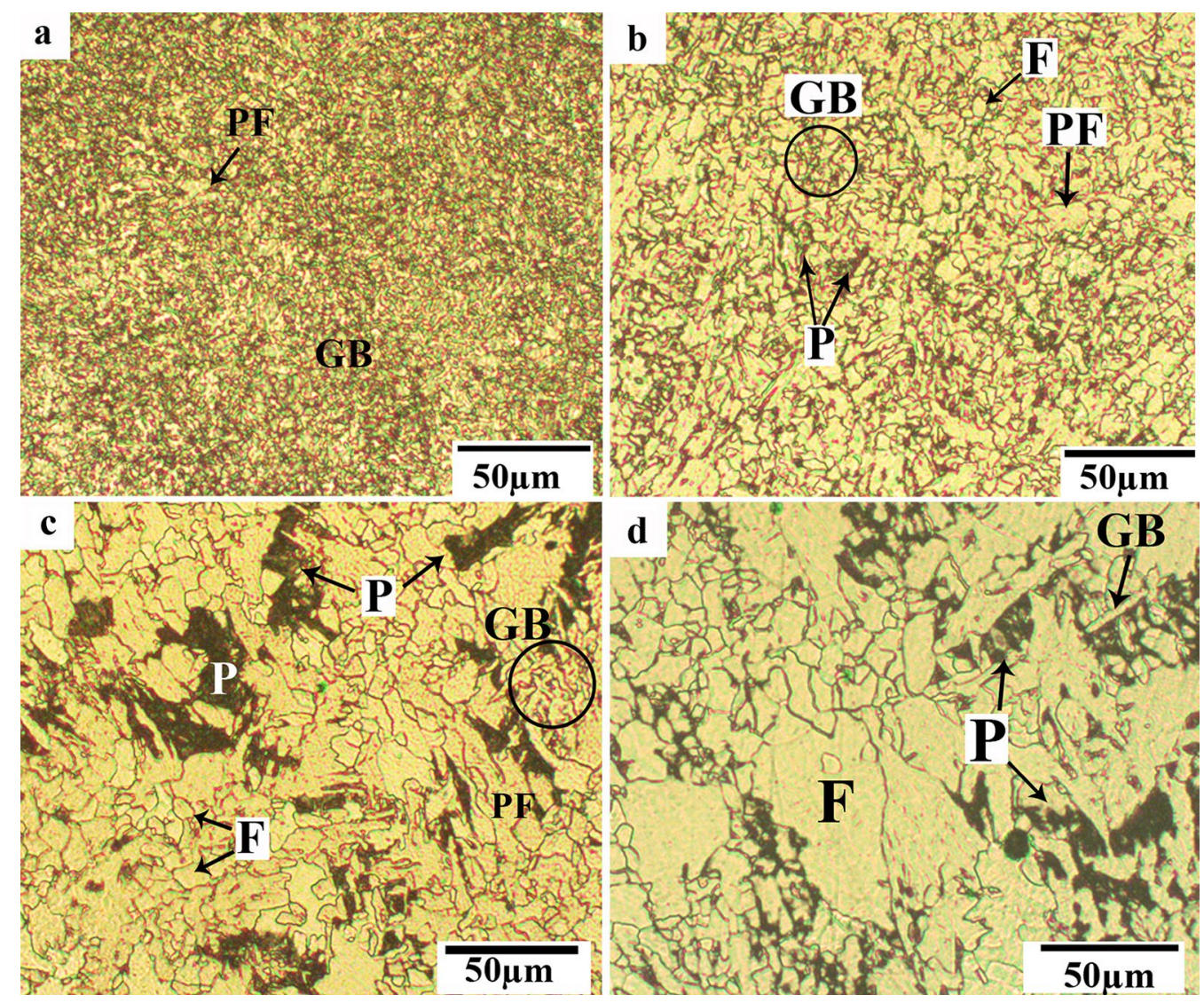

Fig. 6 Micrographs of the middle layers of DLMD samples: a AR500, b AR700, c AR900, d AR1100. Granular bainite (GB), proeutectoid ferrite $(\mathrm{PF})$, pearlite $(\mathrm{P})$

lines were drawn on micrographs and average grain size was calculated using the following formula:

Average grain size $=$ Actual line length $/$ Number of intercepts.

Figure 12 shows that the grain size increases with increasing laser power. It is interesting to notice that the grain sizes of the samples which were deposited in Ar chamber are higher than those of the relevant samples in the atmospheric environment. This can be related to the different amounts of thermal accumulation in samples in different environments. The heat dissipation through a surrounding environment depends on the thermal conductivity around environment. Because the thermal conductivity of air is higher than that of $\mathrm{Ar}$ (9.4 W/K for air and $6.2 \mathrm{~W} / \mathrm{k}$ for Ar at $100 \mathrm{k}$, and $45.7 \mathrm{~W} / \mathrm{k}$ for air and $30.6 \mathrm{~W} / \mathrm{k}$ for Ar at $600 \mathrm{~K}$ ), the heat sinking ability of Ar is lower than air and this can increase the thermal accumulation in Ar-protected samples.

\subsection{Defects in DLMD samples}

The presence of defects is one of the factors affecting mechanical properties in deposited samples. Void is one of the most important DLMD defects which forms easily due to the complex nature of metal formation during deposition. Figure 13 shows the total number and area of voids which were measured in $64 \mathrm{~mm}^{2}$ area in two cross sections of the DLMD samples. It can be seen that increasing laser power from $500 \mathrm{~W}$ to $1100 \mathrm{~W}$ constantly decreases the total area and number of voids. Furthermore, there is a significant reduction of number and size of voids in samples which were deposited in Ar chamber in comparison with the atmospheric deposited samples. Low value of elongation in samples L500 and L700 and also AR500 and AR700 can be associated with the higher amount of voids in these samples. Voids in the microstructure can act as nucleation sites for large dimples and microvoids which lead to the brittle fracture without a considerable amount of plasticity [20].

Figure 14a, b shows some voids in sample L500. The presence of round-shaped voids and some coalescent voids suggests that voids occur because of gas entrapment inside molten pool. When laser power is low and the solidification rate is high, the entrapped gas cannot exit from microstructure. Figure $14 \mathrm{c}$ and d shows some voids in sample AR500. From this figure, one can see that the void morphology in sample AR500 is quite different from sample L500. Voids 


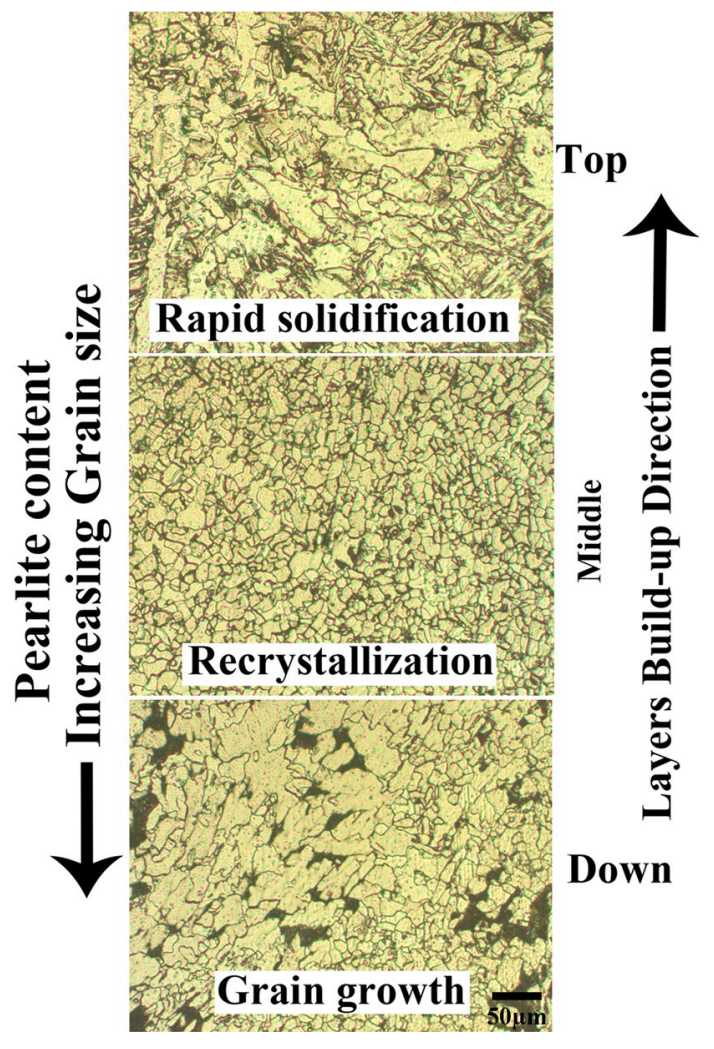

Fig. 7 Microstructures of different parts of sample AR1100 showing the effect of heat accumulation on the microstructure of sample

have a smaller area with triangle shape and sharp edges, with some residual particles inside voids which suggest another type of voids in laser-deposited samples in Ar-protected chamber. In this sample, the molten metal vapor or unmelted particles which can absorb entrapped gas bubbles form the voids inside deposited layers. The black arrows show the entrapped unmelted particles or molten metals inside voids.

Figure 15a shows the fracture surface of sample L500 containing some big holes. The sizes of these holes are same. The internal surface of the holes seems to be intact. In the adjacent area of the hole, some "river patterns" of

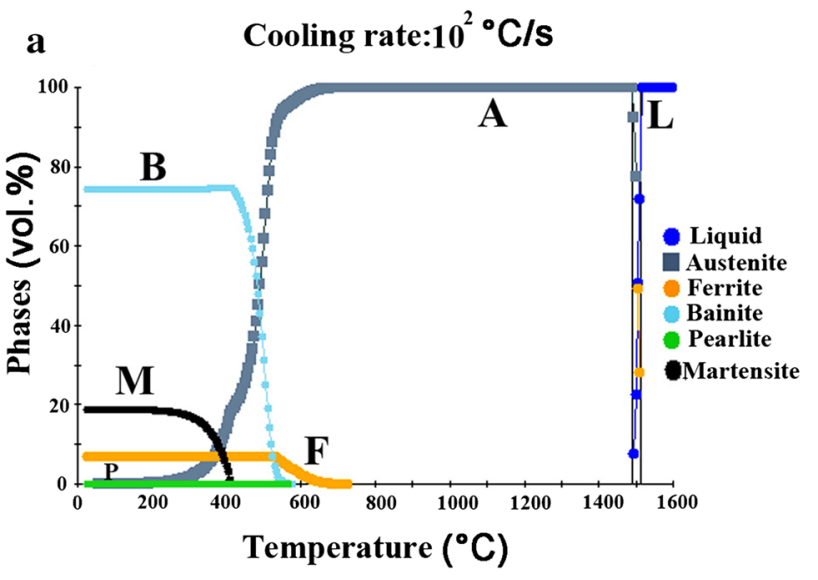

b Cooling rate:50 ${ }^{\circ} \mathrm{C} / \mathrm{s}$

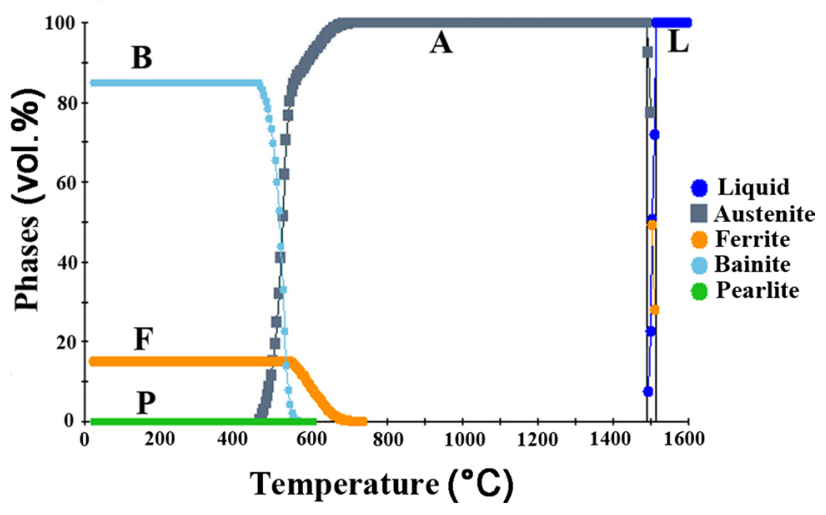

Fig. 8 Phase evolution in the steel $12 \mathrm{CrNi} 2$ in two different cooling rates: a $100{ }^{\circ} \mathrm{C} / \mathrm{s}, \mathbf{b} 50^{\circ} \mathrm{C} / \mathrm{s}$

radiating lines are formed by a mechanism known as cleavage and is characteristic of a brittle fracture. Beside this river-like area, there is "cup and cone" pattern which is formed by a mechanism known as microvoid coalescence and is characteristic of a ductile fracture. The appearance of both types of fracture features can be considered as a mixed brittle-ductile fracture in this sample, resulting in low elongation of $7.54 \%$. On the other hand, fracture surface
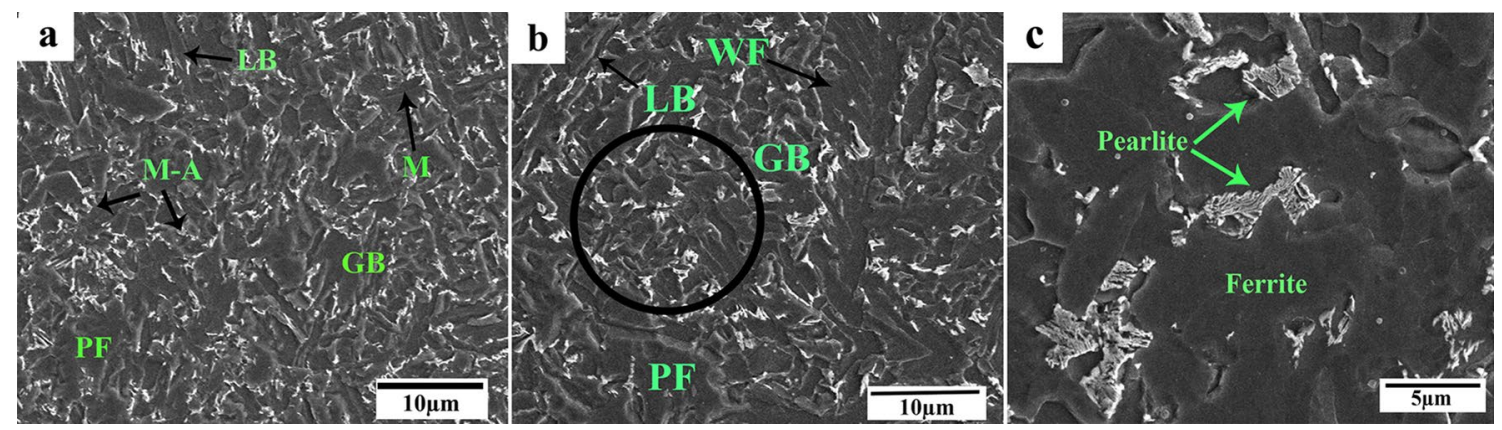

Fig. 9 SEM images of DLMD samples: a AR500, b AR700 top layer, c AR700 middle layer. Lath bainite (LB), granular bainite (GB), proeutectoid ferrite (PF), martensite (M), Widmanstatten ferrite (WF), martensite-austenite constitutes (M-A) 

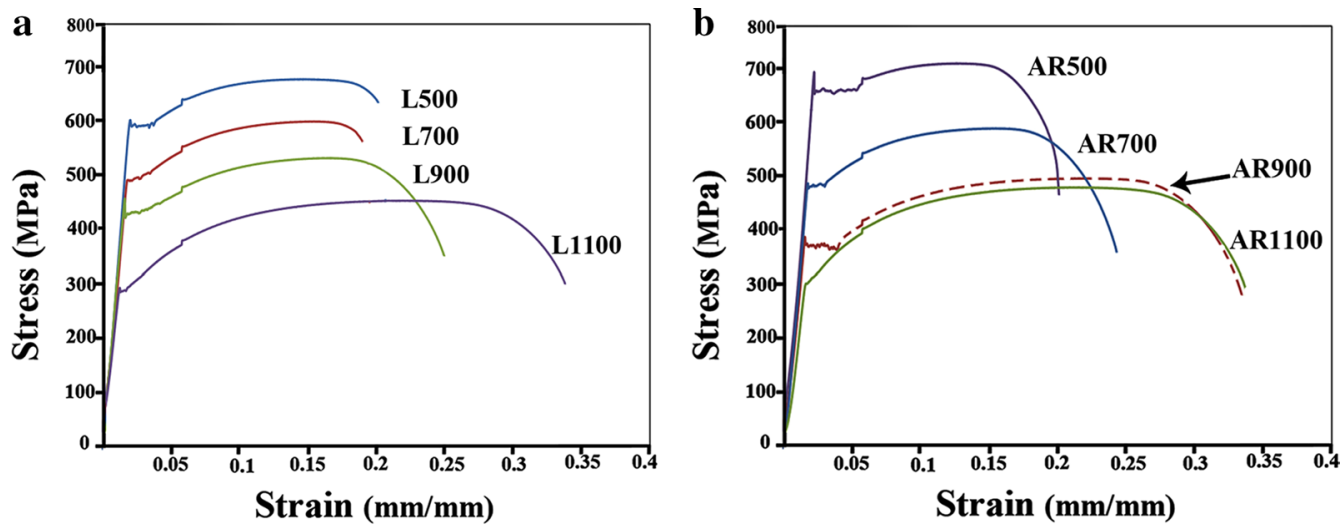

Fig. 10 Stress-strain curves of tensile test samples: a samples deposited in air, $\mathbf{b}$ samples deposited in Ar-protected chamber

Table 3 Mechanical test results of DLMD samples

\begin{tabular}{|c|c|c|c|c|c|}
\hline Sample name & Environment condition & $\sigma_{0.2}(\mathrm{MPa})$ & $\sigma_{\text {uts }}(\mathrm{MPa})$ & $e(\%)\left[\left(L_{\mathrm{f}}-L_{0}\right) / L_{0}\right]$ & $\begin{array}{l}\text { Product of strength } \\
\text { and plasticity (GPa) }\end{array}$ \\
\hline L500 & Deposited in atmospheric condition & $584 \pm 2$ & $659 \pm 2$ & $7.5 \pm 0.3$ & 5.0 \\
\hline L700 & & $482 \pm 1$ & $580 \pm 2$ & $7.5 \pm 0.5$ & 4.4 \\
\hline L900 & & $409 \pm 11$ & $510 \pm 3$ & $10 \pm 1.1$ & 5.1 \\
\hline L1100 & & $284 \pm 20$ & $442 \pm 7$ & $14.2 \pm 1.2$ & 6.2 \\
\hline AR500 & Deposited in Ar-purged chamber & $650 \pm 20$ & $695 \pm 15$ & $8.7 \pm 0.2$ & 6.0 \\
\hline AR700 & & $468 \pm 8$ & $583 \pm 4$ & $9.4 \pm 0.7$ & 5.5 \\
\hline AR900 & & $362 \pm 12$ & $488 \pm 4$ & $15.9 \pm 0.8$ & 7.8 \\
\hline AR1100 & & $300 \pm 8$ & $467 \pm 7$ & $18.8 \pm 1$ & 8.8 \\
\hline
\end{tabular}
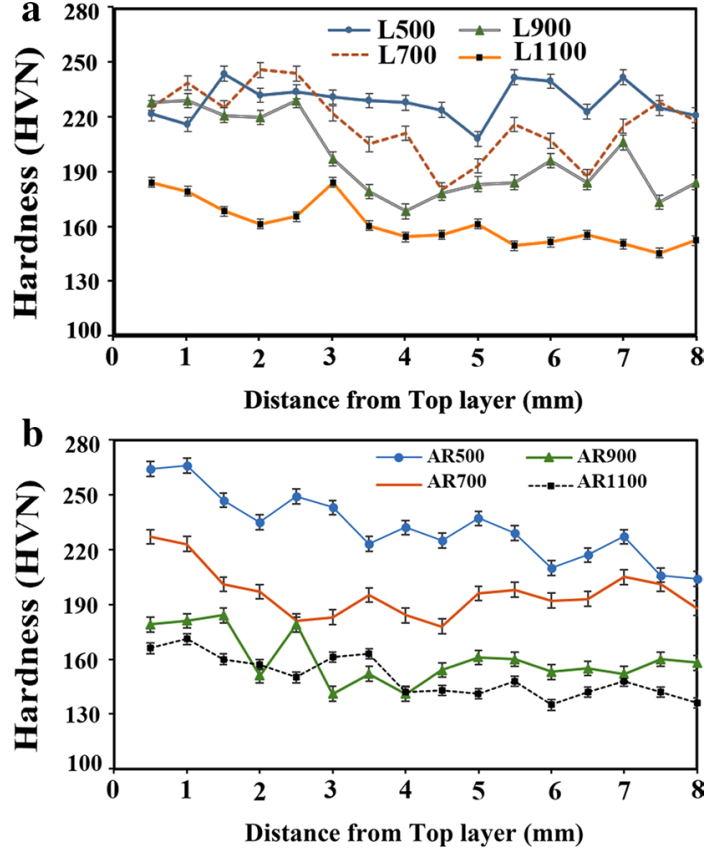

Fig. 11 Vickers hardness of different samples: a atmospheric deposited samples, b Ar-protected samples of sample L1100 shows more ductile features (elongation of $14.1 \%)$. Sample L1100 shows extensive necking before fracture. Fracture surface was covered by many primary voids. Small and big dimple-shaped holes and some voids which formed due to the ductile fracture can be seen on the fracture surface (Fig. 15b). No visible cleavage fracture surface can be seen in this sample. Figure 15c shows EDX analysis of an oxide particle located at a big void in sample L500 which debonded from matrix on the fracture surface of the tensile test sample. Oxide particles and voids in the atmospheric deposited samples are the most important sites for crack nucleation and final failure of the tensile samples. 


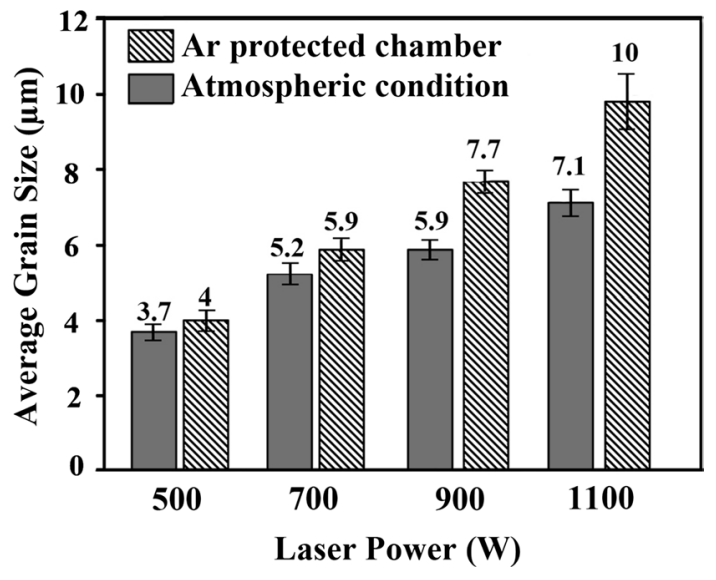

Fig. 12 Grain size measurement results for DLMD samples using intercept method

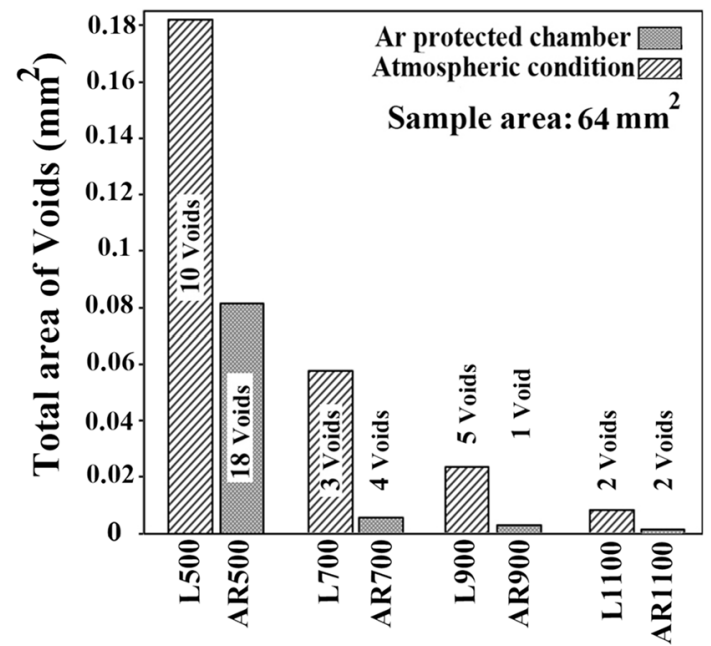

Fig. 13 Total number and area of voids in different samples
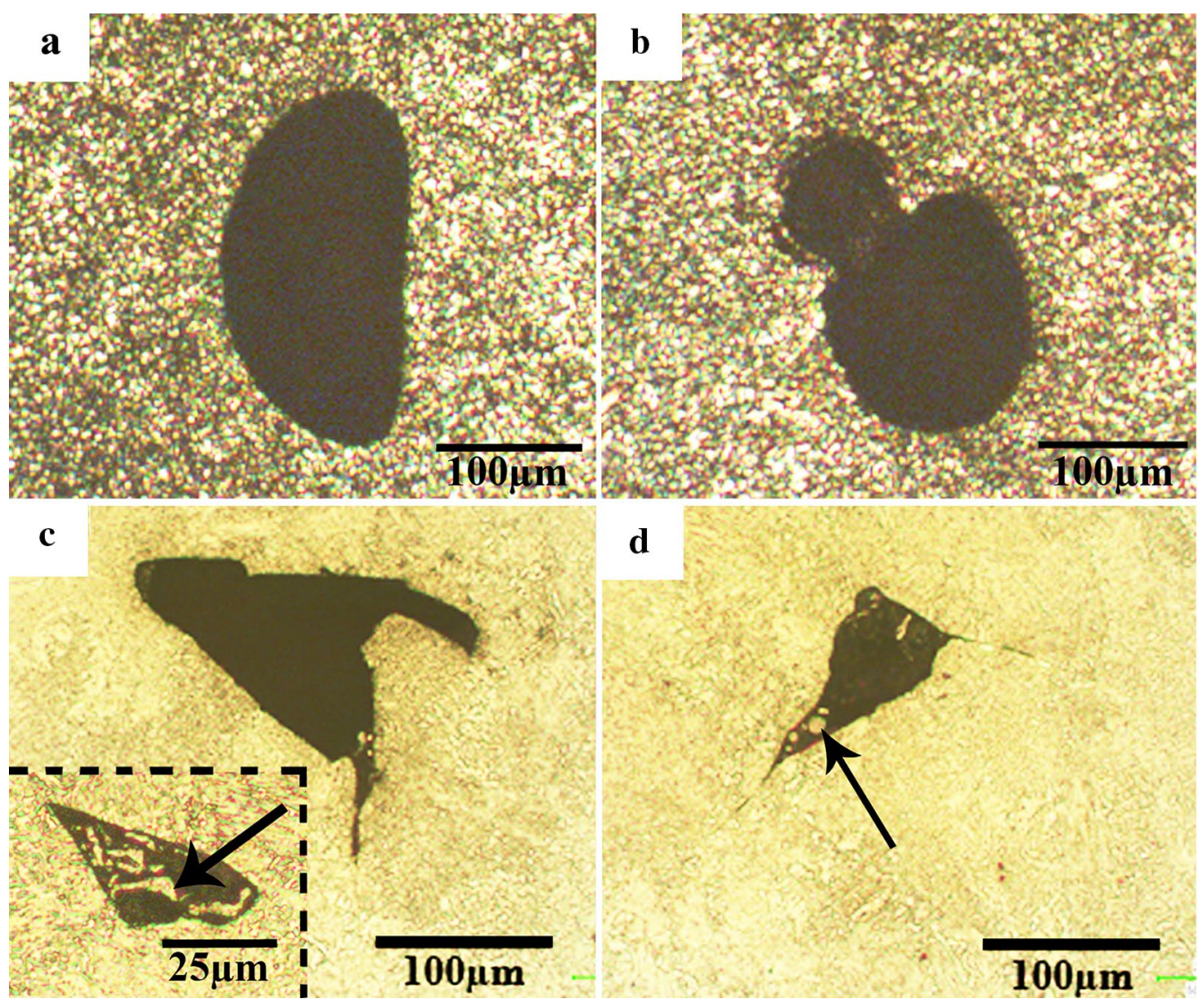

Fig. 14 Shapes and morphologies of voids in DLMD samples: a, b sample L500, $\mathbf{c}, \mathbf{d}$ sample AR500. The black arrows show unmelted powder particles inside voids 

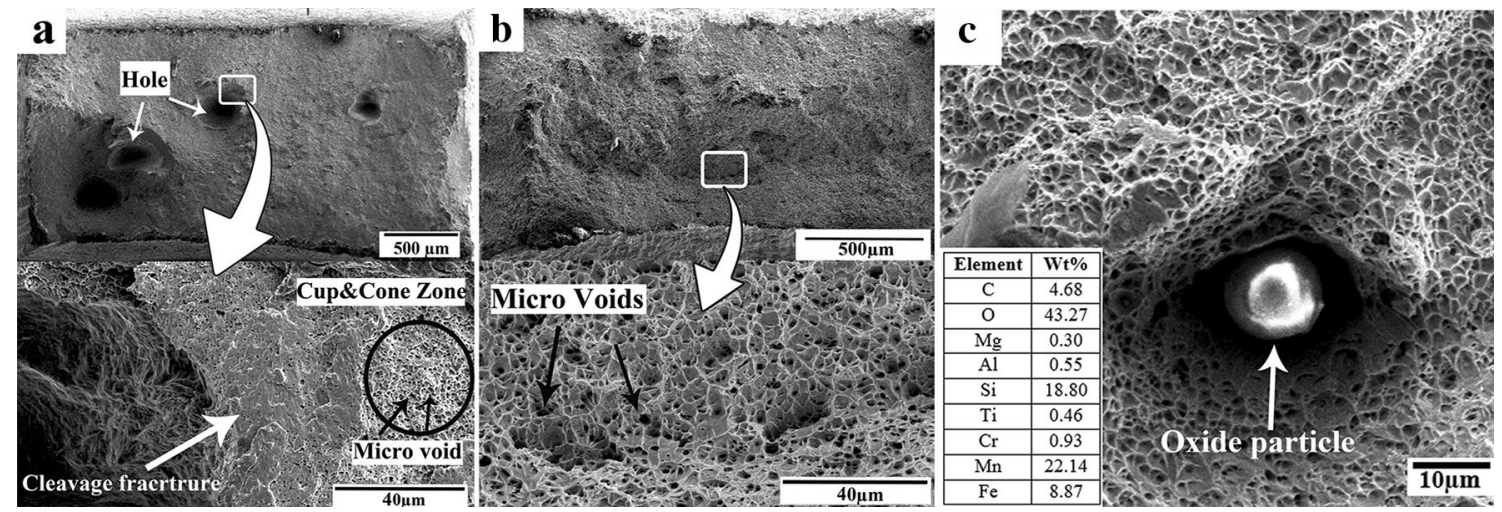

Fig. 15 Fracture surfaces of tensile test samples: a sample L500 consists of ductile fracture accompanied by some holes and cleavage fracture beside holes, b sample L1100 has complete ductile fracture mode, $\mathbf{c}$ oxide particle leads to the void formation in the sample

\section{Conclusion}

Direct laser metal deposition of steel $12 \mathrm{CrNi} 2$ was carried out using four different laser powers in two different deposition environments. It was shown that microstructure and mechanical properties of as-deposited samples strongly depend on the laser power. With increasing laser power, microstructures of samples changed from bainite to the ferrite-pearlite in top layers and equiaxed ferrite grains alongside degenerate pearlite in middle and bottom layers due to the recrystallization. The most defects in deposited samples were voids which decreased with increasing laser power. Deposition in Ar-protected chamber can also decrease the amount of voids in DLMD samples. Using a diode laser with a spot diameter size of $2 \mathrm{~mm}$, laser power of $900 \mathrm{~W}$ is suitable for producing crack- and void-free samples. However, post-deposition heat treatment is necessary for obtaining homogeneous desired microstructure and grain size in the manufactured samples.

Acknowledgements This work was financially supported by the National Key Research and Development Program of China (No. 2016YFB1100203)

\section{References}

[1] S.D. Sun, Q. Liu, M. Brandt, V. Luzin, R. Cottam, M. Janardhana, G. Clark, Mater. Sci. Eng. A 606, 46 (2014)

[2] F. I. Azam, A. Majdi Abdul Rani, K. Altaf, T. V.V.L.N. Rao, H. Aimi Zaharin, An IOP Conf. Ser.: Mater. Sci. Eng. 328, 012005 (2018)
[3] J.X. Fang, S.Y. Dong, S.B. Li, Y.J. Wang, B.S. Xu, J. Li, B. Liu, Y.L. Jiang, Mater. Sci. Eng. A 748, 119 (2019)

[4] Z. Dong, H. Kang, Y. Xie, C. Chi, X. Peng, Mater. Lett. 236, 214 (2019)

[5] S. Chen, R. Wang, J. Ma, J. Liang, T. Cui, C. Liu, Inter. Conf. Mater. Sci. Bio. Eng. (ICMSBE 2017), 102 (2017)

[6] S. Chen, R. Wang, X. Chen, J. Liang, C. Liu, J. Laser. Appl. 30, 032020 (2018)

[7] Y. Zhou, S. Chen, X. Chen, T. Cui, J. Liang, C. Liu, Mater. Sci. Eng., A 742, 150 (2019)

[8] D. Wang, C.T. Chi, W.Q. Wang, Y.L. Li, M.S. Wang, X.G. Chen, Z.H. Chen, X.P. Cheng, Y.J. Xie, J. Mater. Sci. Technol. 35, 1315 (2019)

[9] T. Amine, J.W. Newkirk, F. Liou, Appl. Therm. Eng. 73, 498 (2014)

[10] T. Amine, J.W. Newkirk, F. Liou, Int. J. Adv. Manuf. Technol. 73, 1739 (2014)

[11] P. Farahmand, R. Kovacevic, Opt. Laser Technol. 63, 154 (2014)

[12] I.Y. Pyshmintsev, A.N. Boryakova, M.A. Smirnov, N.V. Dement, Metallurgist 53, 45 (2009)

[13] X.L. Han, D.Y. Wu, X.L. Min, X. Wang, B. Liao, F.R. Xiao, Metals 6, 75 (2016)

[14] Y.C. Jung, S.J. Kim, Y. Ohmori, Metal. Mater. 4, 125 (1998)

[15] H.K.D.H. Bhadeshia, Bainite in Steels. Theory and Practice, third ed., (Maney Publishing, Wakefield, 2015) pp. 6-127

[16] H.K.D.H. Bhadeshia, D.V. Edmonds, Acta Metal. 28, 1265 (1980)

[17] E.P. Klier, T. Lyman, Trans. Am. Inst. Min. Eng. 158, 395 (1944)

[18] Q. Wang, S. Zhang, C. H. Zhang, C. L. Wu, L. Ren, J. Q. Wang, J. Chen, Acta Metall. Sin. (Engl. Lett.) 31, 19 (2018)

[19] G. Dieter, Mechanical metallurgy (McGraw-Hill Book Company, New York, 1961), pp. 370-371

[20] R.A. Hardin, C. Beckermann, Metall. Mater. Trans. A 44, 5316 (2013) 